\title{
The effects of competition outcomes on health: Evidence from the lifespans of U.S. Olympic medalists ${ }^{\text {ts }}$
}

\author{
Adriaan Kalwij \\ Utrecht University School of Economics, PO Box 80125, 3508 TC Utrecht, the Netherlands
}

\section{A R T I C L E I N F O}

\section{Article history:}

Received 11 April 2018

Received in revised form 13 September 2018

Accepted 2 October 2018

Available online 10 October 2018

\section{JEL classification:}

C41

I14

$\mathrm{Z2}$

Keywords:

Duration analysis

Health

Mortality

Inequality

Socioeconomic status

\begin{abstract}
A B S T R A C T
This paper investigates the effects of competition outcomes on health by using U.S. Olympic medalists' lifespans and medal colors as a natural experiment. Whereas the life expectancies of gold and bronze medalists do not differ significantly, life expectancy of silver medalists is about 2.4 and 3.9 years less than these former, respectively. These findings are readily explainable by insights from behavioral economics, psychology, and human biology, which suggest that (perceived) dissatisfactory competition outcomes may adversely affect health. Competition outcomes that affect socioeconomic status (SES) could, therefore, play an important causal role in the positive SES-health gradient among the general population.
\end{abstract}

(C) 2018 The Author. Published by Elsevier B.V. This is an open access article under the CC BY-NC-ND license (http://creativecommons.org/licenses/by-nc-nd/4.0/).
I think, if I was an Olympic athlete, I would rather come in last than win the silver, if you think about it. You know, you win the gold, you feel good. You win the bronze, you think, "Well, at least I got something." But if you win that silver, that's like, "Congratulations, you almost won." Of all the losers, you came in first of that group ... You're the number one loser.

Jerry Seinfeld, 1998

Both by nature and through institutional design, competitions are an integral part of human lives, from college entrance exams and scholarship applications to jobs, promotions, contracts, and awards. Competition outcomes can particularly affect socioeconomic status (SES), which is often empirically measured by income, education, wealth, or occupation. This paper aims to provide insights into competition outcomes' causal role in the well-documented positive and persistent association between SES and health or lifespan (Kitagawa and Hauser, 1973; Duleep, 1989; Marmot et al., 1991; Smith 1999; Huisman et al., 2004; Cutler et al.,

\footnotetext{
is I thank the USC Dornsife Center for Economic and Social Research, University of Southern California, for its hospitality throughout the time spent working on this paper. I furthermore thank the editor, referees, and seminar participants at Erasmus University Rotterdam, ISER (University of Essex), LISER (Luxembourg), VU University Amsterdam and Utrecht University for their discussions and constructive comments.

E-mail address: a.s.kalwij@uu.nl (A. Kalwij).
}

2006; Dow and Rehkopf, 2010; Cutler et al., 2011; Evans et al., 2012; Mackenbach et al., 2016).

One channel though which competition outcomes could seemingly affect individual health is SES, whose positive effect on health could explain the positive association between SES and health or lifespan (hereafter, the SES-health gradient). ${ }^{1}$ An argument supporting this positive effect, albeit one that may have become less relevant over time in developed countries, is that low SES is associated with poverty and accompanying health problems. Balan-Cohen (2008), for example, finds that a senior income assistance program implemented in the U.S. between 1930 and 1955 reduced mortality among poor elderly men through, among other factors, a decrease in infectious diseases. A second supporting argument is that those with higher SES engage in less risky health behavior (Balia and Jones, 2008; Stringhini et al., 2010), which could explain the positive effect of education on health and lifespan (Kawachi et al., 2010; Van Kippersluis et al., 2011). A third argument is that low SES individuals live in more stressful environments and experience more adverse events than high SES individuals. Such adverse events, and the concomitant

\footnotetext{
${ }^{1}$ Other explanations for this gradient include a health effect on SES (Currie and Madrian, 1999; García-Gómez et al., 2013) and the consequences of early life circumstances on later life health and SES (Barker, 1997; Case et al., 2005).
} 
emotional responses, may negatively impact health by increasing the levels of "bad" stress hormones (McEwen and Sapolsky, 1995; Brunner, 1997; McEwen, 1998; Baum et al., 1999; Kubzansky et al., 1999; Seeman et al., 2001; Cohen et al., 2006; Juster et al., 2010; McEwen and Gianaros, 2010). ${ }^{2}$ Matthews et al., (2010), however, in their literature overview, conclude that there is no strong causal evidence in support of this psychosocial argument, although they recognize its potential relevance for the health consequences of the work-related stress generated by low control, effort-reward imbalance, job insecurity, or job loss (Karasek, 1979; Siegrist, 1996; Kristenson et al., 2004; Siegrist and Marmot, 2004; Kuhn et al., 2009; László et al., 2010; Lipowicz et al., 2016). ${ }^{3}$ Stress is also associated with risky health behavior (Kouvonen et al., 2005; Umberson et al., 2008), such as smoking or excessive alcohol consumption. Nonetheless, the empirical evidence to support the above arguments tend to be mostly based on associations, so the economics literature in general concludes that there is no strong empirical evidence for an SES effect on health or mortality in developed countries (Smith, 1999; Cutler et al., 2011; Cesarini et al., 2016).

On the other hand, insights from behavioral economics, psychology, and human biology suggest that although competition outcomes can affect health, it may not be through their effect on SES but through the appraisals of these outcomes. Although the gains and losses of competition are often well defined and can affect SES, individuals are not emotionless-they have affective responses that may depend on both factual and counterfactual outcomes (Kahneman and Miller, 1986; Kahneman and Varey, 1990; Roese, 1997; Epstude and Roese, 2008). Thus, an individual's emotional appraisal of his or her own competition performance (a stressor) serves as a cognitive mediator of coping and the related psychological stress reaction (Lazarus, 1993; Lupien et al., 2007). ${ }^{4}$ Because the stress hormones released in this situation (e.g., glucocorticoids) are neurotoxic and adversely affect health (Sapolsky et al., 1986; Sapolsky, 2000,2005; Epel et al., 2004; Lupien et al., 2007; McEwen 2007,2008), competition outcomes could be a third factor explaining the SES-health gradient (Cutler et al., 2011). If so, it would mean that they can affect both SES and health.

The aim of this paper, therefore, is to empirically test whether competition outcomes affect health through their effects on SES or through the appraisals of these outcomes. To this end, the analysis takes advantage of U.S. Olympic medalists' lifespans and medal colors as a natural experiment, using the former to assess health and the latter to measure competition outcomes. As detailed in the next section, if the ranking of Olympic sports competition outcomes is positively related to medalist SES and unrelated to medalist health at the start of the Olympics, two predictions can be made that relate to the two previous explanations for a positive SES-health gradient among the general population: First, if a competition outcome affects health through its effect on SES (i.e., SES affects health positively) and not through other channels, gold medalists should have the highest life expectancy; bronze medalists, the lowest life expectancy; and silver medalists,

\footnotetext{
2 These and other studies cited here show that stress hormones related to psychological stress affect the immune and endocrine systems, which may impair tissue growth and repair; increase the risk for hypertension, diabetes, arterial disease, and infectious diseases; and hasten aging.

${ }^{3}$ Furthermore, outcomes of financial decisions could affect testosterone and stress (cortisol) levels (Nofsinger et al., 2018).

${ }^{4}$ Lazarus (1993), in his delineation of different stress types, defines psychological stress as harm, that is psychological damage caused by, for instance, an irrevocable loss that leads to emotion-focused coping and is associated with sadness. Lupien et al. (2007), on the other hand, refers to it as a relative stressor (as opposed to absolute stressors like heat, exercise, or hunger) that necessitates a cognitive interpretation in order to elicit a response that might lead to a physiological reaction.
}

somewhere between the two. Second, if a competition outcome affects health through the appraisal of the outcome and not through other channels, then gold and bronze medalists should have the same but silver medalists a lower life expectancy. This latter prediction assumes that gold and bronze medalists tend to appraise their medals as a win, while silver medalists tend to appraise their second place as a loss and, through the associated psychological stress, have their health compromised and life expectancy reduced.

Estimating the effects of medal color on Olympic medalist lifespan and empirically testing these predictions should then throw light on competition outcomes' causal role in the positive SES-health gradient among the general population. More specifically, empirical support for prediction one would suggest that competition outcomes that affect SES contribute to the positive SES-health gradient by SES affecting health. Empirical support for prediction two would suggest that competition outcomes that affect SES contribute to the positive SES-health gradient by the appraisals of the outcomes affecting health. On the other hand, if the empirical relation between medal color and life expectancy cannot be reconciled with either of these two predictions, then the empirical evidence can be inconclusive regarding competition outcomes' implications for the SES-health gradient in general.

In an experimental study related to this paper, Rablen and Oswald (2008) demonstrate that the life expectancy of a Nobel Prize winner is one to two years longer than that of a nonwinning nominee, which they suggest is consistent with an SES effect on life expectancy. Their somewhat cautious conclusion is supported by Redelmeier and Singh (2000) finding that Academy Award winners for Best Actor or Best Actress have a four-year longer life expectancy than nonwinning nominees. ${ }^{5}$ It is also suggested by Leive's (2018) empirical evidence for the U.S. that the higher postOlympic wages of silver medalists in track and field relative to gold medalists may account for the former's lower mortality rate. On the other hand, Clarke et al. (2012) find no statistically significant differences between the life expectancies of gold, silver, and bronze Olympic medalists, suggesting that their health is unaffected by competition outcomes. This finding might, however, be the result of their pooling data from many countries with no regard for cultural or institutional differences. ${ }^{6}$ This present study's first contribution to the literature is that, in contrast to Clarke et al. (2012), it draws a sample exclusively from the Unites States, a country in which sports are socially ingrained and have been professionalized since the early $20^{\text {th }}$ century (Davies, 2012). If, therefore and based on the arguments discussed above, there is a relationship between medal color and life expectancy, one would expect it to be present for the U.S. This U.S. medalist sample is much larger and arguably less selective than the one used by Leive $(2018)^{7}$. Even more important, and yielding the second contribution to the literature, the analysis in this present study explicitly considers, in contrast to Leive (2018), bronze medalists whose lifespans enable an empirical distinction between the effects of competition outcomes on health through their effect on SES or through the appraisals of these outcomes.

\footnotetext{
5 On the other hand, Sylvestre et al. (2006), find that these Academy Award winners' gain in life expectancy is actually smaller and not statistically significant. ${ }^{6}$ For example, athletes' appraisals of, and the SES related to, Olympic competition outcomes might depend on how much a country's general population cares about medal color and this latter's (relative) rewards.

7 The selectiveness of Leive's (2018) U.S. sample of Olympic track and field medalists is reflected in his finding that among this sample, silver medalists have a lower mortality rate than gold medalists. The data described in Section 2 cover the same Olympics and when only applying the selection criterium of non-missing dates of births and deaths, I find for a sample of 139 U.S. track and field medalists that, on average, silver medalists live about 1.5 years less than gold medalists.
} 
The paper is structured as follows: Section 1 discusses how medal color can affect U.S. medalists' life expectancies, after which Section 2 describes the data. Section 3 then outlines the statistical model, and Section 4 presents the empirical results, which are interpreted in Section 5. Finally, Section 6 summarizes the main findings and discusses their implications for the SES-health gradient among the general population.

\section{U.S. Olympic medalists' life expectancy: two predictions}

In the U.S., the professionalization of sports competitions, together with the accompanying money and fame, began as early as the mid- $19^{\text {th }}$ century. After the professionalization of baseball in the Northeast in 1869 , other sports gradually followed suit until sports professionalization had spread across the nation (Davies, 2012). The importance of sports in the U.S. is exemplified by the central role played by sports competitions in the country's education system since the first half of the $20^{\text {th }}$ century (Davies, 2012). This professional environment ensures that U.S. athletes are well prepared and strongly incentivized to excel.

The best three outcomes of Olympic sports competitions have a clear ordering: the winners receive a gold medal; the runners-up, a silver medal; and those in third position, a bronze medal. Historically, however, even though the first modern Olympics took place in 1896 in Athens, Greece, third place prizes were not introduced until the 1904 Olympics, when they were also retroactively awarded to third-place winners of the 1896 and 1900 Olympics. Except for boxing, judo, taekwondo, and wrestling, in which the bronze medals go to eliminated semi-finalists (boxing) or winners of repechage brackets, most Olympic sports that use a knockout format have a third-place game to determine who wins the bronze.

Against this background, with gold an objectively better outcome than silver, and the latter a better outcome than bronze, the empirical analysis assumes an increasing monotonic relation between the ranking of Olympic sports competition outcomes and medalist SES. That is, it is assumed that during their lives, on average, gold medalists have the highest; bronze medalists the lowest SES; and silver medalists' SES somewhere between the two. A second assumption is that, because all U.S. Olympic medalists are elite athletes, their health at the start of the Olympics is unrelated to the color of medal won. ${ }^{8}$ Accordingly, the medalists' SES, as measured by medal color, should be unrelated to their health at the time of the Olympics. At the same time, it should be noted that although maintaining these two assumptions in the analysis is arguable reasonable and necessary to clear exposition, their relaxation, to a certain extent, leaves the main conclusion of this paper unchanged (see Section 5).

In particular, these assumptions enable two predictions about medalist life expectancies that relate to the two possible explanations for a positive SES-health gradient among the general population. The first explanation, a positive SES effect on health, is empirically testable because it predicts that gold medalists (with the highest average SES) will have the highest life expectancy; bronze medalists, the lowest; and silver medalists, somewhere in between. The second explanation, that the appraisals of competition outcomes affect health, finds support in behavioral economics, psychology, and human biology. In the framework of counterfactual thinking (Kahneman and Miller, 1986; Kahneman and Varey, 1990; Markman et al., 1993; Roese, 1997; Epstude and Roese, 2008), an individual

\footnotetext{
${ }^{8}$ In support of this assumption, Leive (2018) interprets the finding that gold and silver medalists are of similar height as evidence of no health differences between medalists at the time of the Olympics. I also refer to Leive (2018) for an excellent discussion on the exogeneity of medal color when analyzing its effect on mortality.
}

(here, an Olympic medalist) appraises a competition outcome (medal color) ex post as a win or a loss. According to Medvec et al. (1995), Medvec and Savitsky (1997), and David and Willingham, (2006), silver medalists on average appraise their medals as a loss and are ex post dissatisfied, while bronze and gold medalists on average appraise them as a win and are ex post satisfied with their outcomes. ${ }^{9}$ As further expounded by Medvec et al. (1995), whereas gold medalists appraise the outcomes as wins, which leads to satisfaction, silver medalists make close counterfactuals with bronze and gold medalists and allow the thought "I almost ..." to dominate their feelings. For these latter, a bronze medal would add little, so they are left with an appraisal of having lost gold and a feeling of dissatisfaction with their silver medal. Hence, for silver medalists, this upward counterfactual comparison reduces satisfaction. Bronze medalists, in contrast, discount the silver, as it would add little, and make a close counterfactual comparison with fourth place, which is a big difference with bronze as it would have left them with no medal, so their feelings are dominated by "At least I . . ..". For bronze winners, therefore, this downward counterfactual comparison increases satisfaction and prompts an appraisal of their medals as a win. ${ }^{10}$ Empirical findings in Medvec et al. (1995) are in support of these theoretical arguments. Based on video footage of medalists' immediate reactions after the Olympic sports competitions and of the award ceremonies, they find that, on average, silver medalists look less satisfied than bronze medalists with their medals and that this is unrelated to how well they were expected to perform. In additional they find, based on video footage of interviews with medalists, that silver medalists' counterfactual thoughts were more focused on "I almost" (won gold) and bronze medalists' counterfactual thoughts were more focused on "at least I" (won bronze/a medal).

In the above analyses, medal color and fourth place are considered close counterfactuals; that is, counterfactuals whose outcomes are within the medalists' reach. Such close counterfactual comparisons exemplify the concept of emotional amplification (Kahneman and Miller, 1986), which in the Olympic context is facilitated by the natural ordering of the sports competition outcomes and the very close performances of the medalists (Medvec and Savitsky, 1997). Further amplification may also occur because of the significance assigned to the stressor in the ex post appraisal (Lazarus, 1993), which might be particularly relevant for Olympic medalists. That is, for Olympians, winning a medal follows many years of dedication to the sport, a sustained long-term effort that is likely to intensify affective responses (Van Dijk et al., 1999). Moreover, Olympic athletes often have only one chance at a medal, making its loss not only irreversible but subject to a lifetime of regret, a likely ingredient for psychological harm (Lazarus, 1993).

Given the above arguments, it seems probable that the Olympic credo of "It is more important to participate than to win" (Young, 1994) fails to reflect most silver medalists' feelings, and that, on average, they appraise silver medals won as gold medals lost and are dissatisfied with their ultimate rankings. As previously pointed out, this dissatisfaction leads to the secretion of stress hormonespossibly over an extended time period given the young age at which most silver medalists experience dissatisfaction-which compromises their health. This adverse effect on health of appraising a competition outcome as a loss (i.e., a dissatisfactory

\footnotetext{
${ }^{9}$ I use the word "(dis)satisfaction" in order to distinguish this paper from those that employ the term "disappointment" for a psychological reaction to a comparison of an ex ante expectation with an actual competition outcome (Bell, 1985; Loomes and Sugden, 1986). In addition, Herbert (1955), in a rational agent model, introduces a pay-off function based on satisfactory and unsatisfactory outcomes rather than a continuous utility function.

10 McGraw et al., (2005) suggest an alternative interpretation, arguing that silver medalists are disappointed because they expected gold, whereas bronze medalists are satisfied because they did not expect to win a medal.
} 
Table 1

Sample frequencies by olympics*.

\begin{tabular}{|c|c|c|c|c|c|c|}
\hline Cells: Frequencies & Medalists $^{\mathrm{a}}$ & Women $^{\mathrm{b}}$ & $\begin{array}{l}\text { Gold } \\
\text { medals }\end{array}$ & Silver medals & Bronze medals & Alive $^{\mathrm{c}}$ \\
\hline 1904 St. Louis (S) & 246 & 5 & 108 & 120 & 114 & 0 \\
\hline 1906 Athens (S) & 14 & 0 & 9 & 6 & 6 & 0 \\
\hline 1908 London (S) & 52 & 0 & 32 & 16 & 15 & 0 \\
\hline 1912 Stockholm (S) & 73 & 0 & 45 & 25 & 36 & 0 \\
\hline 1920 Antwerp (S) & 132 & 8 & 111 & 45 & 37 & 0 \\
\hline 1924 Paris $(\mathrm{S})$ & 156 & 15 & 96 & 36 & 49 & 0 \\
\hline 1924 Chamonix (W) & 12 & 1 & 1 & 10 & 1 & 0 \\
\hline 1928 Amsterdam (S) & 76 & 16 & 47 & 24 & 17 & 0 \\
\hline 1928 St. Moritz (W) & 13 & 1 & 6 & 6 & 2 & 0 \\
\hline 1932 Los Angeles (S) & 168 & 21 & 81 & 46 & 61 & 1 \\
\hline 1932 Lake Placid (W) & 32 & 2 & 10 & 21 & 3 & 0 \\
\hline 1936 Berlin (S) & 86 & 14 & 51 & 29 & 16 & 1 \\
\hline 1936 Garmisch-Partenkirchen (W) & 16 & 0 & 2 & 0 & 14 & 0 \\
\hline 1948 London $(S)^{d}$ & 2 & 0 & 1 & 1 & 1 & 0 \\
\hline 1948 St. Moritz $(W)^{d}$ & 1 & 0 & 0 & 1 & 0 & 0 \\
\hline 1904-1948 Olympics & & & 600 & 386 & 372 & \\
\hline
\end{tabular}

Notes: $\mathrm{S}=$ summer games; $\mathrm{W}=$ winter games.

" The 1908 and 1920 games included several Winter Olympics sports events.

a A total of 978 medalists; the column total is 1,079 because about 9.6 percent of the medalists won medals at more than one Olympics.

b A total of 67 female medalists. The column total is 83 because about 24 percent of female medalists won medals in more than one Olympics.

c On December 31, 2014. Evelyn Furtsch (born 1914; 1932 Los Angeles; athletics) passed away in 2015 and Adolph Kiefer (born $1918 ; 1936$ Berlin; swimming) passed away in 2017 (see, e.g., https://en.m.wikipedia.org).

d Three athletes (Earl Thomson, Jack Heaton, and Miguel de Capriles) won medals in both the 1936 and 1948 Olympics.

outcome) leads to the second prediction that bronze and gold medalists should have the highest and silver medalists the lowest life expectancy.

\section{Data}

The data on the U.S. Olympic medalists are taken from Sports Reference, 2014, an online data source currently being incorporated into the statistical section of the International Olympic Committee's web site. In addition to athletes' Olympic sports achievements, this data set also includes Olympic medalists' vital statistics. As previously mentioned, however (Section 1), no third place prizes were awarded at the 1896 and 1900 Olympics, so medalists at these Olympics are excluded from the sample, which also affects seven medalists from the 1904, 1906 and 1908 Olympics who won their first medals at the 1900 Olympics. Also excluded are those who won their first medal after the 1936 Olympics (that being the 1948 Olympics at the earliest) because missing death dates could mean that they are either still alive or have passed away but on an unknown date. On the other hand, because all except one such medalist from the earlier Olympics were born in the $19^{\text {th }}$ century ${ }^{11}$, almost all medalists with missing death dates can reasonably be assumed to be deceased. The raw sample thus consists of 1,014 U.S. medalists who won their first medal at the Olympics between 1904 and 1936. A further 22 medalists are dropped because of unknown birth and death dates and 14 medalists are dropped because of unknown death dates. The final sample consists of 978 medalists.

This paper also makes use of population mortality rates taken from the 1900-2014 life tables provided by the U.S. Social Security Administration (Bell and Miller, 2005) and the Human Mortality Database (2017). This latest available life table information is merged with the medalist sample data by gender, age, and year of birth to yield annual population mortality rates based on these variables (see Appendix Fig. A1).

Table 1 lists the information by Olympics for the final sample of 978 U.S. medalists. Three Olympic medalists who had already won a

\footnotetext{
11 The one exception is Manuela Kalili (1932 Olympics), born in 1912.
}

medal at the 1936 Olympics also won medals at the 1948 Olympics (bottom two rows). Two medalists were still alive on December 31, 2014 (last column). The distribution of medal colors shows that U.S. medalists have won gold medals relatively often (600 out of 1,358 medals). Medalists' ages at the time of win and lifespans measured in full years are calculated based on the years of birth, death, and the Olympics. As Table 2 shows, the medalists' median lifespan of 75 years is five years higher than that of the general population. The gender difference in median lifespan among Olympic medalists is 6 years in favor of women and resembles that of the general population (not reported in the table).

When examining life expectancy and survival rates by medal color in Table 2 and Fig. 1, the color is determined by a medalist's best overall Olympic performance. It is gold for medalists who have won at least one gold medal, silver for those who have won at least one silver medal but no gold medals, and bronze for those who have won at least one bronze medal but no silver or gold medals during their lives. Fig. 1 then reveals that the survival function of bronze medalists for the whole age range lies above that of gold medalists, whose survival function in turn lies above that for silver medalists. These survival function differences translate into gold medalists' median lifespan that is four years longer than that of silver medalists and two years shorter than that of bronze medalists (Table 2). Medalists who either won more than one medal or won medals at more than one Olympics, however, have a shorter lifespan than medalists who won one medal or won medals at one Olympics (see Appendix Tables A1 and A2 for number of medalists and lifespan distribution by Olympics and Olympic sports). Additional unreported results from log-rank tests reject the null hypotheses of survival function equality by gender, medal color, sports, Olympics, more than one medal won, and medals won at more than one Olympics. Furthermore, log-rank tests reject the null-hypothesis of equal survival functions of gold and silver medalists and of bronze and silver medalists while the nullhypothesis of equal survival functions of gold and bronze medalists is not rejected.

\section{Mortality rate model}

The effects of medal color on lifespan, after controlling for other observed characteristics, are estimated using a proportional 
Table 2

Lifespan distribution by medalist characteristic.

\begin{tabular}{|c|c|c|c|c|}
\hline & \multirow[t]{2}{*}{ Number of medalists } & \multicolumn{2}{|c|}{ Lifespan (in years) } & \multirow[b]{2}{*}{ 75th percentile } \\
\hline & & 25th percentile & 50th percentile & \\
\hline General population $^{\mathrm{a}}$ & & 58 & 70 & 80 \\
\hline All medalists & 978 & 64 & 75 & 84 \\
\hline Male medalists & 911 & 63 & 75 & 83 \\
\hline Female medalists & 67 & 70 & 81 & 89 \\
\hline Bronze medalist (best performance) & 243 & 66 & 78 & 86 \\
\hline Silver medalist (best performance) & 277 & 62 & 72 & 82 \\
\hline Gold medalist (best performance) & 458 & 64 & 76 & 84 \\
\hline One medal & 757 & 64 & 76 & 85 \\
\hline More than one medal & 221 & 61 & 72 & 81 \\
\hline Won medals at one Olympics & 892 & 64 & 76 & 84 \\
\hline Won medals at more than one Olympics & 86 & 63 & 71 & 79 \\
\hline
\end{tabular}

a Based on a weighted average of mortality rates of the U.S. medalists' national cohorts and gender, conditional on reaching 25 (the average age at which medalists won their medals).

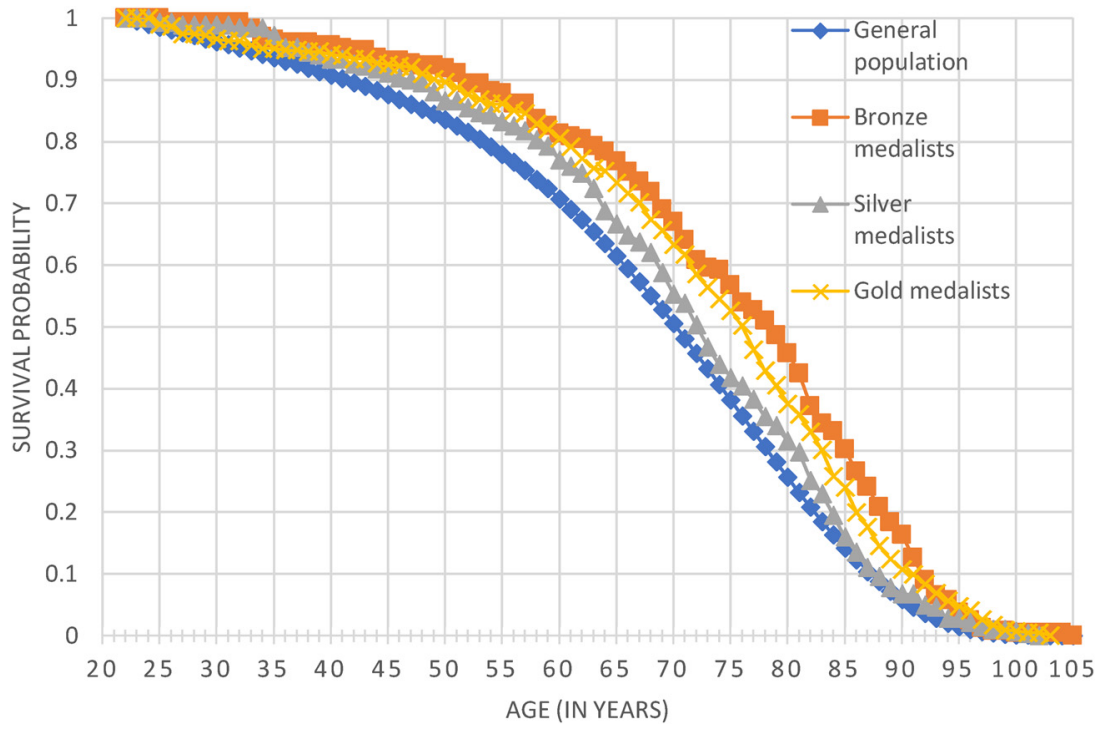

Fig. 1. Survival functions. Medal color is based on best overall performance. All medalists survived to at least age 23 .

hazard rate model (Cox, 1972) in which the mortality rate of medalist $i$ at age $t$ with covariates $\boldsymbol{x}_{i}(t)$ is defined as follows:

$\lambda\left(t \mid c_{i}, g_{i}, \boldsymbol{x}_{i}(t), \boldsymbol{\beta}\right)=\lambda_{c_{i} g_{i}}(t) \exp \left(\boldsymbol{x}_{i}(t)^{\prime} \boldsymbol{\beta}\right)$

where $\lambda_{c_{i} g_{i}}(t)$ is the population mortality rate at age $t$ for individuals born in year $c_{i}$ of gender $g_{i} \cdot \boldsymbol{x}_{i}(t)$ includes a constant, and the covariates are allowed to vary with age to accommodate medalists winning medals at more than one Olympics. For a dummy variable, as are all covariates except age, the exponent of the corresponding $\mathrm{k}^{\text {th }}$ element of the parameter vector $\beta, \exp \left(\beta_{k}\right)$, is the odds ratio corresponding to this covariate. This means, (exp $\left.\left(\beta_{k}\right)-1\right)$, when multiplied by 100 , is interpreted as the percentage increase in the mortality rate for a unit increase in the dummy variable (from 0 to 1 ).

Because lifespan is measured in full years, a discrete-time proportional hazard rate model is estimated (see, e.g., Cameron and Trivedi, 2005) in which medalist age measured in full years $a$ is assumed constant within a calendar year and the covariates are constant on the age interval $[a, a+1$, with $a \in\{0,1,2, . ., A\}$. A is the maximum lifespan of medalists in full years. Given (1), the probability that a medalist is dead at age $a+1$, conditional on being alive at age $a$, can be written as

$\lambda^{d}\left(a \mid c_{i}, g_{i}, \boldsymbol{x}_{i}(a), \boldsymbol{\beta}\right)=1-\exp \left(-\mu_{c_{i} g_{i}}(a) \exp \left(\boldsymbol{x}_{i}(a)^{\prime} \boldsymbol{\beta}\right)\right)$ with $\mu_{c_{i} g_{i}}(a)=\int_{a}^{a+1} \lambda_{c_{i} g_{i}}(s) d s$.

The parameter estimates are obtained by maximum likelihood from a sample of $n$ medalists:

$$
\begin{aligned}
\hat{\boldsymbol{\beta}}= & \operatorname{argmax}_{\boldsymbol{\beta}} \log \prod_{i=1}^{n} \prod_{a=A_{0 i}}^{A_{i}}\left(\exp \left(-\mu_{c_{i} g_{i}}(a) \exp \left(\boldsymbol{x}_{i}(a)^{\prime} \boldsymbol{\beta}\right)\right)\right)^{1-m_{i a+1}} \\
& \times\left(1-\exp \left(-\mu_{c_{i} g_{i}}(a) \exp \left(\boldsymbol{x}_{i}(a)^{\prime} \boldsymbol{\beta}\right)\right)\right)^{m_{i a+1}}
\end{aligned}
$$

where $A_{i}$ is the age of medalist $i$ in the last year alive or in 2013 if the medalist is still alive at the end of the observation period (December 31, 2014). ${ }^{12} A_{0 i}$ is the age of winning the first Olympic medal, and $m_{i a+1}$ is equal to 1 if medalist $i$ turned $a$ years old and died during the age interval $(a, a+1)$; 0 otherwise.

$\mu_{c_{i} g_{i}}$ is the annual population mortality rate among the general population (from the U.S. life tables; see Section 2) with the same age $a$, birth year $c_{i}$ and gender $g_{i}$ as medalist $i$. By using annual population mortality rates as specified in (2), the mortality rate model can flexibly control for gender differences; an age gradient; the time effects (e.g., due to medical advances or adverse health

\footnotetext{
12 Because no life table information is available from 2015 onward, the lifespans of two medalists are right censored at December 31, 2014 (see Table 1).
} 
events such as the 1918 Spanish flu epidemic); and different gender, age, and time effects across cohorts. As expressed in (1), the medalists' age-specific mortality rates are assumed to be proportional to the age-specific population mortality rates for individuals with the medalist's same birth year and gender, although the inclusion of time-variant covariates also allows the proportionality factor to vary with age. Likewise, gender and age are included as covariates to permit gender-based mortality differences and the mortality age gradient to vary between medalists and the general population. The proportionality assumption embedded in the mortality rate model is assessed by adding interactions between the covariates and age and testing the null hypothesis that all parameters corresponding to these interactions are equal to 0 .

Also included as a covariate is a medalist's best Olympic performance up to and including age $a$, whether it be a bronze, silver, or gold medal. This inclusion enables testing of the two different predictions made in Section 1: (i) Gold medalists will have the highest and bronze medalists the lowest life expectancy, and (ii) silver medalists have a lower life expectancy than bronze and gold medalists. The model also includes covariates indicating whether more than one medal was won and whether medals were won at more than one Olympics up to and including age $a$. These two covariates control for possible adverse health effects from a more intensive or longer period of training (Maffetone and Laursen, 2016), which also provides more opportunities for a better overall Olympic performance. Finally, because the selection of Olympic athletes may vary over time and because U.S. medalists' performances may vary by sports, the model also controls for different Olympics and different sports, which latter could also be related to mortality risk (Clarke et al., 2012; Antero-Jacquemin et al. 2014).

\section{Empirical results}

In line with Clarke et al. (2012), the estimates of model 1 (Table 3 ) show that at age 25 Olympic medalists have about a 45 percent lower $(100 \times(\exp (-0.60)-1))$ mortality rate than the general population. As medalists grow older, however, this mortality advantage decreases by a significant ${ }^{13} 0.8$ percentage points per year until it vanishes around age 100 . On the other hand, as reported by Coate and Sun (2013), the insignificant effect of "Female medalist" suggests that gender differences in Olympic medalists' mortality rates resemble those in the general population.

The results for model 2, which includes medal color based on medalists' best performances, indicate that, at every age, the mortality rate of a silver medalist is 36 percent higher (100 x (exp $(0.31)-1) ; p$-value $=0.0005$ ) than that of a bronze medalist (the omitted reference category). The mortality rate of a gold medalist, in contrast, does not differ significantly from that of a bronze medalist $(p$-value $=0.0955)$.

The model 3 results show that controlling for having won more than one medal, having won medals at more than one Olympics, sports type, and different Olympics does not affect the estimated effects of medal color on mortality rate: The mortality rate of a silver medalist is 36 percent higher $(p$-value $=0.0013$ ) than that of a bronze medalist and the mortality rate of a gold medalist does not differ significantly from that of a bronze medalist ( $p$-value $=$ 0.1880 ). There are no jointly significant effects of sports type on

\footnotetext{
${ }^{13}$ In discussing the empirical findings, I draw conclusions based on a 5 percent level of statistical significance. The reported $p$-values and levels of significance (at the 1 and 5 percent levels) provide as well insights into possible issues related to multiple comparisons tests being carried out.
}

Table 3

Estimation results.

\begin{tabular}{|c|c|c|c|}
\hline $\begin{array}{l}\text { Mortality rate model } \\
\text { Covariate }\end{array}$ & $\begin{array}{l}\text { Model } 1 \\
\text { Coeff. } \\
(S E) \\
\end{array}$ & $\begin{array}{l}\text { Model } 2 \\
\text { Coeff. } \\
(S E) \\
\end{array}$ & $\begin{array}{l}\text { Model } 3 \\
\text { Coeff. } \\
(S E) \\
\end{array}$ \\
\hline Constant & $\begin{array}{l}-0.60^{* *} \\
(0.10)\end{array}$ & $\begin{array}{l}-0.77^{* *} \\
(0.12)\end{array}$ & $\begin{array}{l}-0.97^{* *} \\
(0.18)\end{array}$ \\
\hline Female medalist & $\begin{array}{l}0.01 \\
(0.13)\end{array}$ & $\begin{array}{l}0.02 \\
(0.13)\end{array}$ & $\begin{array}{l}0.00 \\
(0.14)\end{array}$ \\
\hline Age (in years, minus 25$)^{a}$ & $\begin{array}{l}0.008^{* *} \\
(0.002)\end{array}$ & $\begin{array}{l}0.008^{* *} \\
(0.002)\end{array}$ & $\begin{array}{l}0.012 * * \\
(0.002)\end{array}$ \\
\hline Gold medalist (best performance is gold) ${ }^{\mathrm{b}}$ & & $\begin{array}{l}0.13 \\
(0.08)\end{array}$ & $\begin{array}{l}0.13 \\
(0.10)\end{array}$ \\
\hline Silver medalist (best performance is silver) ${ }^{\mathrm{b}}$ & & $\begin{array}{l}0.31^{* *} \\
(0.09)\end{array}$ & $\begin{array}{l}0.31^{* *} \\
(0.10)\end{array}$ \\
\hline Won more than one medal & & & $\begin{array}{l}0.10 \\
(0.11)\end{array}$ \\
\hline Won medals at more than one Olympics & & & $\begin{array}{l}0.31^{*} \\
(0.15)\end{array}$ \\
\hline Control for sports type & No & No & Yes \\
\hline Control for different Olympics & No & No & Yes \\
\hline Number of medalists & 978 & 978 & 978 \\
\hline Number of parameters & 3 & 5 & 35 \\
\hline $\begin{array}{l}\text { Value log-likelihood function }(/ 1,000) \\
\text { Null hypothesis; cells contain p-values }\end{array}$ & & & \\
\hline No gender and age effects & $0.001^{* *}$ & $0.000^{* *}$ & $0.000^{* *}$ \\
\hline No effects of medal color & & $0.002^{* *}$ & $0.003^{* *}$ \\
\hline No effects of more than one medal or Olympics & & & $0.002^{* *}$ \\
\hline No effects of sports type & & & 0.564 \\
\hline No effects of different Olympics & & & $0.001^{* *}$ \\
\hline A proportional hazard specification & 0.329 & 0.565 & 0.085 \\
\hline
\end{tabular}

Notes: The coefficient estimates (Coeff.) are of parameter vector $\beta$ from (1) and standard errors are in parentheses (SE). Statistical significance at the 5 percent level is denoted with * and significance at the 1 percent level with **.

a The average age of medalists competing at the Olympics, 25, is subtracted from age to facilitate the interpretation of the intercept coefficient.

$\mathrm{b}$ The omitted reference category is "bronze medalist" (best performance is bronze).

mortality (third-to-last row) and the effects of the different Olympics (second-to-last row) on mortality, on the other hand, are jointly significant. ${ }^{14}$

Interestingly, having won medals at more than one Olympics increases mortality which suggests possible adverse health effects from a longer period of training (Maffetone and Laursen, 2016). Lastly, the final set of test results (bottom row) indicate no rejection in any of the three models of the null hypothesis that interactions between the covariates and age have no effects on mortality rate. Rather, these results support the proportionality assumption embedded in the mortality rate models.

\subsection{A Robustness checks}

Table 4 reports the outcomes of several robustness tests of potential influences on the model 3 estimation results (Table 3 ). First, because modeling a medalist's best performance (gold, silver, or bronze) ignores the possible effects on health of the number of medals by color, model 4 (Table 4 ) includes these numbers as covariates. Based on the results, an additional bronze or gold medal has no significant effect on the mortality rate, but an additional silver medal significantly increases the mortality rate by about 22 percent $(100 \times(\exp (0.20)-1))$. To avoid any arbitrary choice between modeling best performance or number of medals by color, I then estimate model 4 (or model 3 in Table 3 ) on the basis of a

\footnotetext{
14 Other unreported estimation results indicate that only bobsledding medalists have a significantly higher mortality rate than medalists in athletics (the reference group), possibly because bobsledding is a power sports (Zwiers et al., 2012), and that the effects of the different Olympics on mortality show no interpretable pattern.
} 
Table 4

Robustness checks.

\begin{tabular}{|c|c|c|c|c|c|c|}
\hline $\begin{array}{l}\text { Mortality risk model } \\
\text { Covariate }\end{array}$ & $\begin{array}{l}\text { Model } 4 \\
\text { Coeff. } \\
(S E)\end{array}$ & $\begin{array}{l}\text { Model } 5 \\
\text { Coeff. } \\
(S E)\end{array}$ & $\begin{array}{l}\text { Model } 6 \\
\text { Coeff. } \\
(S E)\end{array}$ & $\begin{array}{l}\text { Model } 7 \\
\text { Coeff. } \\
(S E)\end{array}$ & $\begin{array}{l}\text { Model } 8 \\
\text { Coeff. } \\
(S E)\end{array}$ & $\begin{array}{l}\text { Model } 9 \\
\text { Coeff. } \\
(S E)\end{array}$ \\
\hline Gold medalist $^{\mathrm{a}}$ & & 0.13 & 0.15 & 0.12 & 0.12 & 0.11 \\
\hline (best performance is gold) & & $(0.10)$ & $(0.10)$ & $(0.11)$ & $(0.09)$ & $(0.09)$ \\
\hline Silver medalist ${ }^{\mathrm{a}}$ & & $0.33^{* *}$ & $0.31^{* *}$ & $0.34^{* *}$ & $0.28^{* *}$ & $0.33^{* *}$ \\
\hline (best performance is silver) & & $(0.10)$ & $(0.10)$ & $(0.12)$ & $(0.09)$ & $(0.10)$ \\
\hline Number of gold medals & $\begin{array}{l}0.03 \\
(0.06)\end{array}$ & & & & & \\
\hline Number of silver medals & $\begin{array}{l}0.20^{* *} \\
(0.07)\end{array}$ & & & & & \\
\hline Number of bronze medals & $\begin{array}{l}-0.05 \\
(0.07)\end{array}$ & & & & & \\
\hline Number of medalists & 978 & 757 & 911 & 719 & 952 & 827 \\
\hline Number of parameters & 35 & 33 & 34 & 25 & 35 & 29 \\
\hline Value log-likelihood function $(/ 1,000)$ & -3.92 & -3.04 & -3.65 & -2.90 & -3.82 & -3.32 \\
\hline
\end{tabular}

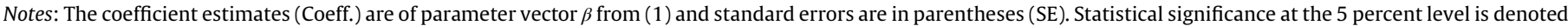
with * and significance at the 1 percent level with **.

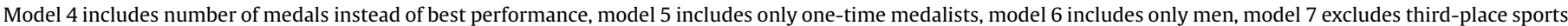

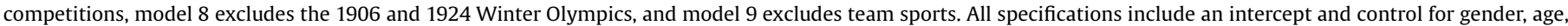

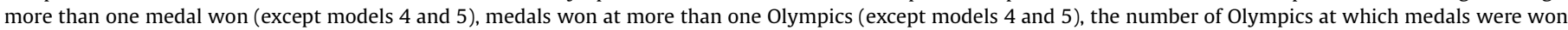
(model 4 only), sports type, and the different Olympics.

a The omitted reference category is "bronze medalist" (best performance is bronze).

subsample of medalists who won only one medal. These estimates (model 5; Table 4) reveal that the effects of medal colors on the mortality rate are virtually identical to those from model 3 (Table 3). These findings could thus be interpreted as support for using medalist best performance in place of number of medals by color.

Second, concerning sample composition, the results for a subsample of men (model 6; Table 4) are very similar to those obtained for a sample of men and women (model 3; Table 3). This similarity, however, probably results from having only 67 women in the sample, which unfortunately prevents a thorough investigation of possible gender differences in medal color effects on mortality rate. Next, as explained in Section 1, not only do several sports hold a third-place competition for bronze in addition to the final competition for silver and gold, but medals won at certain Olympics have been either retroactively downgraded or only retroactively recognized. ${ }^{15}$ Because either change could have influenced appraisals of medal color or the relation between medal color and SES, both could potentially have affected the empirical results. Yet the estimation results from models 7 and 8 (Table 4) show no effects of these events on the model 3 results (Table 3 ). Model 9 (Table 4) further tests the relation between medal color and mortality by checking for any influences of group versus individual events as there might be differences in how medal colors relate to SES or are appraised. Once again, the main model 3 results (Table 3 ) remain robust to the exclusion of team sports.

\subsection{Life expectancy}

The life expectancies of medalists by medal color, calculated based on the model 3 estimates (Table 3), are for men born in 1895 who won their only medal at age 25 (i.e., the sample average) and competed in athletics at the 1920 Antwerp Olympics. ${ }^{16}$ As Table 5 shows, all these medalists have a predicted life expectancy that exceeds that of the general population, one that ranges from about three years for silver medalists to seven years for bronze medalists

\footnotetext{
15 The 1906 Olympics are considered intercalated games and not officially recognized by the International Olympic Committee, while the 1924 Winter Olympics were only made an official Olympic event in 1926.

${ }^{16}$ Due to the proportionality assumption imbedded in the mortality rate model,
} the main conclusions remain when the medalist characteristics are changed. (columns $1 \& 2$ ). The life expectancies of bronze and gold medalists, in contrast, are not significantly different from each other, but silver medalists have a significantly lower life expectancy than either gold or bronze medalists (columns $3 \& 4$ ). More specifically, the life expectancy of silver medalists is about 2.4 and 3.9 years lower than that of gold medalists and bronze medalists, respectively.

Finally, the point estimates suggest that bronze medalists enjoy a higher life expectancy than gold medalists, as also apparent from Fig. 1 and Table 3. While all statistical tests provided on this difference show it is insignificant, some possible explanations for it are that winning a gold medal might have required more intense training over a longer time period, which adversely affects health (Maffetone and Laursen, 2016), that gold medalists pursued lower paid occupations than silver medalists after their sports careers (Leive, 2018), or that the fame and glory associated with winning gold induces risky health behavior (Epstein and Epstein 2013).

\section{Interpretation of the main results}

The primary empirical findings are that both bronze and gold medalists have significantly higher life expectancies than silver medalists, and that life expectancies of bronze and gold medalists do not differ significantly from each other. To interpret these results, I draw on the two assumptions introduced in section 1: (i) an increasing monotonic relation between the ranking of Olympic sports competition outcomes and medalist SES and (ii) no relation between this ranking and medalist health at the start of the Olympics.

Given these two assumptions, the main results, even though they suggest that competition outcomes affect health, do not support the contention that they do so through their effects on SES. Were such the case, then bronze medalists would have a significantly lower life expectancy than silver medalists. Rather, based on the arguments outlined in Section 1, the result that silver medalists have a significantly lower life expectancy than gold and bronze medalists can be interpreted as indicating an adverse effect on health of a (perceived) dissatisfactory competition outcome.

\subsection{Alternative assumptions}

Although these two assumptions for interpreting the empirical results from Section 4 may seem reasonable, their validity could always be called into question. It is therefore worth noting that 
Table 5

Predicted life expectancy by medal color.

\begin{tabular}{|c|c|c|c|c|}
\hline Cells: Years & $\begin{array}{l}\text { Life expectancy } \\
\text { Prediction }\end{array}$ & $\begin{array}{l}\text { Difference from population life expectancy } \\
\text { Prediction }\end{array}$ & $\begin{array}{l}\text { Difference from bronze medalist } \\
\text { Prediction }\end{array}$ & $\begin{array}{l}\text { Difference from gold medalist } \\
\text { Prediction }\end{array}$ \\
\hline Population & 67.73 & & & \\
\hline Bronze medalists & $\begin{array}{l}74.76^{* *} \\
(1.46) \\
{[0.000]}\end{array}$ & $\begin{array}{l}7.03^{* *} \\
(1.46) \\
{[0.000]}\end{array}$ & & \\
\hline Silver medalists & $\begin{array}{l}70.84^{* *} \\
(1.21) \\
{[0.000]}\end{array}$ & $\begin{array}{l}3.11^{*} \\
(1.21) \\
{[0.010]}\end{array}$ & $\begin{array}{l}-3.92^{* *} \\
(1.06) \\
{[0.000]}\end{array}$ & $\begin{array}{l}-2.38^{*} \\
(1.04) \\
{[0.022]}\end{array}$ \\
\hline Gold medalists & $\begin{array}{l}73.23^{* *} \\
(1.44) \\
{[0.000]}\end{array}$ & $\begin{array}{l}5.49^{* *} \\
(1.44) \\
{[0.000]}\end{array}$ & $\begin{array}{l}-1.54 \\
(1.14) \\
{[0.178]}\end{array}$ & \\
\hline
\end{tabular}

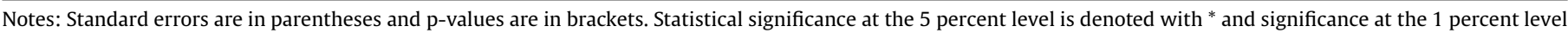
with ${ }^{* *}$.

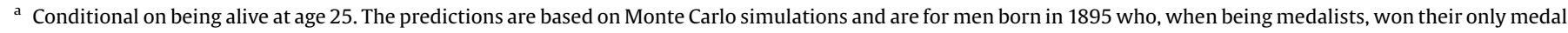
in athletics at the 1920 Antwerp Olympics at age 25.

both assumptions can be relaxed to a certain extent without affecting the above interpretations. As regards (i), if SES affects health, assuming a decreasing rather than increasing monotonic relation between SES and Olympic competition outcome rankings ${ }^{17}$ would predict a higher life expectancy for silver medalists than for gold medalists, an observation for which Table 5 provides no support. On the other hand, assuming no relation between SES and the outcome rankings would not allow an assessment based on Olympic medalists data of whether SES affects health. Nevertheless, even if there would be no relation between SES and the outcome rankings, the results given in Table 5 can still be interpreted as indicating an adverse effect on health of a dissatisfactory competition outcome. Hence, the above interpretation of the main empirical results holds irrespective of the assumed monotonic relation between SES and Olympic competition outcome rankings.

On the other hand, if rather than assuming no relation, one assumed a monotonically decreasing or increasing relation between outcome rankings and medalist health at the start of the Olympics (ii), ${ }^{18}$ then, if SES affects health, the predictions under a monotonicity assumption could be either a monotonically increasing, monotonically decreasing, or nonexistent relation between the outcome rankings and life expectancy. Table 5, however, supports none of these predictions. However, if competition outcomes affected health through the appraisals of the outcomes, then under this alternative assumption, dependent on the strength of the assumed relation, the predicted nonmonotonic relation between outcome rankings and life expectancies could be tilted. For instance, bronze and gold medalists could have significantly different life expectancies, and one of these could even be lower than the life expectancy of silver medalists. Again, however, Table 5 provides no empirical support for such predictions. Hence, the main empirical results cannot be reconciled with the alternative assumption of a monotonically decreasing or increasing relation between competition outcome rankings and medalist health at the start of the Olympics.

\section{Summary and Discussion}

By estimating the effects of U.S. Olympic medalists' medal colors on their lifespans, this analysis shows that the life expectancies of

\footnotetext{
17 As reflected by Leive's (2018) finding that in a sample of 54 U.S. track and field athletes, silver medalists have, on average, higher post-Olympics earnings than gold medalists.

${ }^{18}$ This alternative assumption would bias the effects of medal colors on life expectancy.
}

bronze and gold medalists differ insignificantly from each other but are significantly higher than the life expectancy of silver medalists. The latter is in fact about 2.4 and 3.9 years lower than those of gold and bronze medalists, respectively. The reduced life expectancy of winning silver can be considered substantial when compared to, for instance, the associations between smoking or education and life expectancy: Compared to non-smokers, smokers have a seven years lower life expectancy (Rogers and Powell-Griner, 1991) and individuals with less than 12 years of schooling have a four years lower life expectancy than individuals who went to college (Kitagawa and Hauser, 1973; Duleep, 1989). Interpreted based on insights from behavioral economics, psychology, and human biology, these findings for U.S. Olympic medalists suggest that whereas, on average, bronze and gold medalists appraise their medals as a win, silver medalists appraise them as a loss (Medvec et al., 1995) and, through the associated psychological stress (Lazarus, 1993), have their health compromised and life expectancy reduced (Epel et al., 2004; Sapolsky, 2005; Lupien et al., 2007, Lupien et al., 2008).

The ultimate purpose of analyzing U.S. Olympic medalists' lifespans is to provide insights into the SES-health gradient among the general population, ${ }^{19}$ whose everyday lives and socioeconomic status (SES) are continually affected by myriad competition outcomes. In this real-world setting, competition outcomes may not provide insights into if health is affected by competition outcomes through their effect on SES or through the appraisals of these outcomes because, for instance, an outcome that is objectively a loss and adversely affects SES may as well be appraised as a loss. In contrast, this paper argues that in the setting of Olympic sports competitions the lifespans of bronze medalists, next to those of silver and gold medalists, enable an empirical distinction between the effects of competition outcomes on health through their effect on SES or through the appraisals of these outcomes. Nonetheless, although an SES effect on health among the general population could explain the SES-health gradient, no empirical support is found for competition outcomes affecting health through their effects on SES, perhaps because medal color is unrelated to medalist SES or because SES does not affect health. Rather, the analysis provides empirical support for individual health being adversely affected by (perceived) dissatisfactory competition outcomes. This paper therefore contributes to the literature by showing that competition outcomes that affect SES could play an important causal role in the SES-health gradient among the general population by also affecting health through their appraisals.

\footnotetext{
19 This paper's main findings should also be of interest to professional athletes in that they suggest there might be a need for mental health care to cope with (perceived) losses.
} 
Although the SES-health gradient and its persistence are a major concern to policymakers, the notion of competition outcomes as a causal third factor in the SES-health gradient has not previously been empirically analyzed in the literature. Further research is thus needed to determine its quantitative importance, and external validity, before any solid policy conclusions can be drawn. Nonetheless, the findings reported in this paper, in line with the policy recommendations put forward by Adler and Newman (2002) and Deaton, (2002), support the idea that health disparities could be reduced by facilitating individual access to (mental) health care when needed.

\section{Appendix A.}

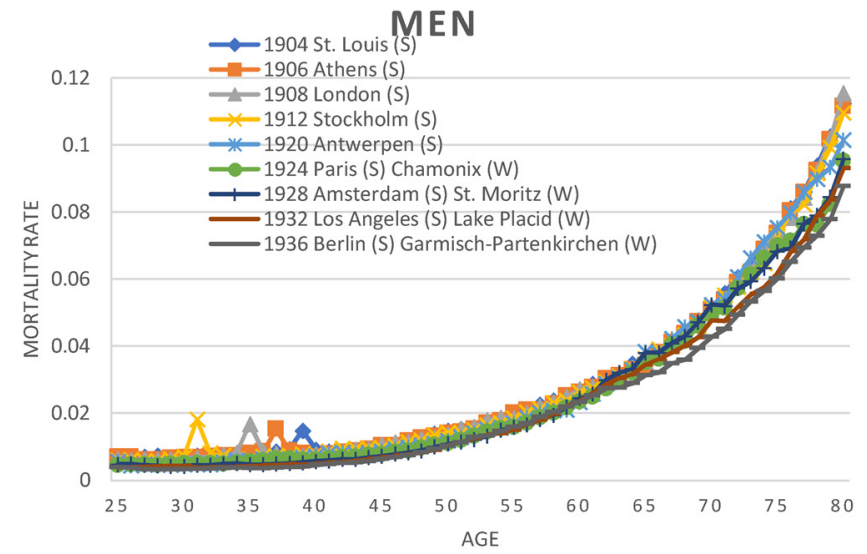

WOMEN

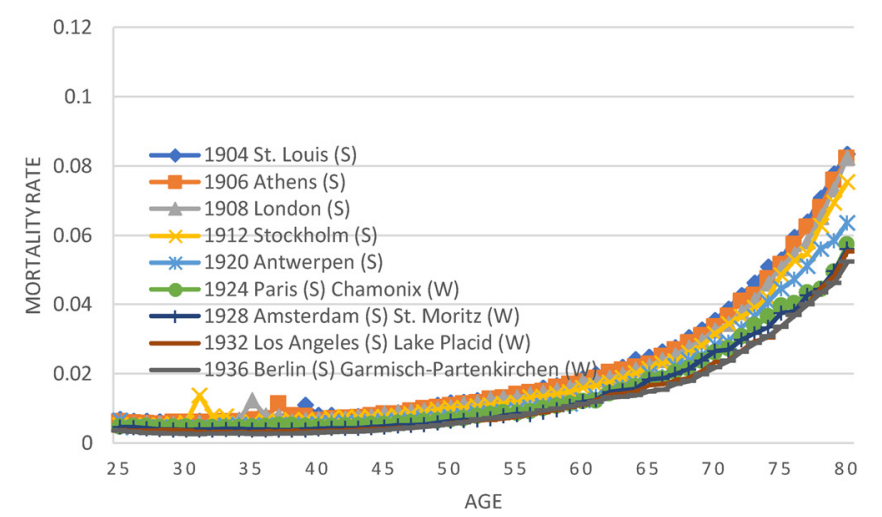

Fig. A1. Annual mortality rates from life tables by gender, age, and year of the olympics.

Table A1

Lifespan distribution by Olympics.

\begin{tabular}{|c|c|c|c|c|}
\hline \multirow[b]{2}{*}{ Olympic Games at which first medal was won } & \multirow[t]{2}{*}{ Number of medalists } & \multicolumn{2}{|l|}{ Lifespan (age) } & \multirow[b]{2}{*}{ 75th percentile } \\
\hline & & 25th percentile & 50th percentile & \\
\hline 1904 St. Louis (S) & 246 & 58 & 70 & 81 \\
\hline 1906 Athens $(S)$ & 7 & 71 & 78 & 84 \\
\hline 1908 London $(S)$ & 42 & 56 & 69 & 78 \\
\hline 1912 Stockholm (S) & 65 & 67 & 75 & 83 \\
\hline 1920 Antwerp (S) & 125 & 66 & 76 & 84 \\
\hline 1924 Paris $(S)$ & 137 & 64 & 76 & 86 \\
\hline 1924 Chamonix (W) & 10 & 71 & 72 & 77 \\
\hline 1928 Amsterdam (S) & 67 & 62 & 79 & 89 \\
\hline 1928 St. Moritz (W) & 12 & 57 & 65 & 77 \\
\hline 1932 Los Angeles (S) & 152 & 69 & 80 & 86 \\
\hline 1932 Lake Placid (W) & 26 & 63 & 71 & 88 \\
\hline 1936 Berlin (S) & 75 & 69 & 81 & 87 \\
\hline 1936 Garmisch-Partenkirchen (W) & 14 & 68 & 71 & 84 \\
\hline
\end{tabular}

Notes: $\mathrm{S}=$ summer games; $\mathrm{W}=$ winter games. The 1908 and 1920 games included several Winter Olympics sports events. 
Table A2

Lifespan distribution by sports.

\begin{tabular}{|c|c|c|c|c|}
\hline \multirow[b]{2}{*}{ Sports } & \multirow[t]{2}{*}{ Number of medalists } & \multicolumn{2}{|l|}{ Lifespan (age) } & \multirow[b]{2}{*}{ 75th percentile } \\
\hline & & 25th percentile & 50th percentile & \\
\hline Athletics & 263 & 64 & 75 & 83 \\
\hline Rowing & 99 & 66 & 77 & 85 \\
\hline Swimming & 81 & 64 & 75 & 86 \\
\hline Ice hockey & 41 & 69 & 76 & 85 \\
\hline Gymnastics & 38 & 62 & 78 & 86 \\
\hline Sailing & 19 & 66 & 80 & 87 \\
\hline Cycling & 16 & 58 & 74 & 83 \\
\hline Fencing & 21 & 66 & 76 & 87 \\
\hline Football & 19 & 56 & 69 & 79 \\
\hline Hockey & 14 & 76 & 82 & 86 \\
\hline Basketball & 14 & 71 & 83 & 87 \\
\hline Shooting & 79 & 64 & 73 & 81 \\
\hline Wrestling & 36 & 63 & 77 & 84 \\
\hline Water polo & 25 & 59 & 73 & 85 \\
\hline Boxing & 32 & 58 & 71 & 84 \\
\hline Bobsledding & 23 & 57 & 65 & 69 \\
\hline Rugby & 38 & 62 & 78 & 85 \\
\hline Equestrianism & 11 & 67 & 74 & 81 \\
\hline Diving & 30 & 62 & 80 & 87 \\
\hline Tennis & 14 & 65 & 72 & 84 \\
\hline Golf & 30 & 52 & 65 & 79 \\
\hline Other sports & 41 & 68 & 75 & 82 \\
\hline
\end{tabular}

Notes: “Other sports” include judo, taekwondo, canoeing, weightlifting, ice skating, skiing, figure skating, and art.

\section{References}

Adler, Nancy E., Newman, Katherine, 2002. Socioeconomic disparities in health: pathways and policies. Health Aff. (Millwood) 21 (2), 60-76.

Antero-Jacquemin, Juliana, Deni, Desgorces Francois, Frederic, Dor, Adrien, Sedeaud, Amal, Haïda, Philippe, LeVan, Toussaint, Jean-François, 2014. Row for your life: a century of mortality follow-up of french olympic rowers. PLoS ONE 9 (11) e113362.

Balan-Cohen, Andreea., 2008. The effect of income on elderly mortality: evidence from the Old age assistance program in the United States. Working Paper. Tufts University.

Balia, Silvia, Jones, Andrew M., 2008. Mortality, lifestyle and socio-economic Status. J. Health Econ. 27 (1), 1-26.

Barker, David J.P., 1997. Maternal nutrition, fetal nutrition and diseases in later life. Nutrition 13 (9), 807-813.

Baum, Andrew, Garofalo, J.P., Yali, Ann M., 1999. Socioeconomic Status and chronic stress. Does stress account for SES effects on health? Ann. N.Y. Acad. Sci. 896, 131-144.

Bell, David E., 1985. Disappointment in decision making under uncertainty. Oper. Res. 33 (1), 1-27.

Bell, Felicitie C., and Michael L. Miller. 2005. "Life Tables for the United States Social Security Area 1900-2100.” Actuarial Study 120 (11-11536). Social Security Administration, Office of the Chief Actuary.

Brunner, Eric., 1997. Socioeconomic determinants of health: stress and the biology of inequality. Br. Med. J. 17, 1472-1476.

Cameron, A..Colin, Trivedi, Pravin K., 2005. Microeconometrics: Methods and Applications. Cambridge University Press, Cambridge, UK.

Case, Anna, Fertig, Angela, Paxson, Christina, 2005. The lasting impact of childhood health and circumstances. J. Health Econ. 24, 365-389.

Cesarini, David, Lindqvist, Erik, Östling, Robert, Wallace, Björn, 2016. Wealth, health, and child development: evidence from administrative data on Swedish lottery players. Q. J. Econ. 131 (2), 687-738.

Clarke, Philip M., Walter, Simon J., Hayen, Andrew, Mallon, William J., Heijmans, Jeroen, Studdert, David M., 2012. Survival of the fittest: retrospective cohort study of the longevity of olympic medallists in the modern era. Br. Med. J. 345, e8308.

Coate, Douglas, Sun, R., 2013. Survival estimates for elite male and female olympic athletes and tennis championship competitors. Scand. J. Med. Sci. Sports 23, $722-727$.

Cohen, Sheldon, Doyle, William J., Baum, Andrew, 2006. Socioeconomic Status is associated with stress hormones. Psychosomatic Med. 68, 414-420.

Cox, David R., 1972. Regression models and life tables. J. R. Stat. Soc. Series B (Methodol.) 34 (2), 187-220.

Currie, Janet, and Brigitte C. Madrian. 1999. "Health, Health Insurance and the Labor Market”. Handbook of Labor Economics, Vol. 3, Orley Ashenfelter and David Card, 3309-3416. Elsevier: North-Holland.

Cutler, David M., Deaton, Angus.S., Lleras-Muney, Adriana, 2006. Determinants of mortality. J. Econ. Perspect. 20 (3), 97-120.

Cutler, David M., Lleras-Muney, Adriana, Vogl, Tom, 2011. Socioeconomic Status and health: dimensions and mechanisms. In: Glied, Sherry, Smith, Peter C. (Eds.), The Oxford Handbook of Health Economics. Oxford University Press, New York.
David, Matsumoto, Willingham, Bob, 2006. The thrill of victory and the agony of defeat: spontaneous expressions of medal winners of the 2004 Athens olympic games. J. Pers. Soc. Psychol. 91 (3), 568-581.

Davies, Richard O., 2012. Sports in American life. A History. John Wiley \& Sons, City: Chichester.

Deaton, Angus, 2002. Policy implications of the gradient of health and wealth. Health Aff. (Millwood) 21, 13-30.

Dow, William H., Rehkopf, David H., 2010. Socioeconomic gradients in health in International and historical context. Ann. N.Y. Acad. Sci. 1186, 24-36 (Issue: The Biology of Disadvantage).

Duleep, Harriet Orcutt., 1989. Measuring socioeconomic mortality differentials over time. Demography 26 (2), 345-351.

Epel, Elissa S., Blackburn, Elizabeth H., Lin, Jue, Dhabhar, Firdaus S., Adler, Nancy E., Morrow, Jason D., Cawthon, Richard M., 2004. Accelerated telomere shortening in response to life stress. Proc the Nat. Acad. Sci. (PNAS) 1001 (49),17312-17315.

Epstein, C.R., Epstein, R.J., 2013. Death in The New York Times: The price of fame is a faster flame, QJM: An International. J. Med. 106 (6), 517-521.

Epstude, Kai, Roese, Neal J., 2008. The functional theory of counterfactual thinking. Personality Soc. Psychol. Rev. 12 (2), 168-192.

Evans, Williams, Wolfe, Barbara, Adler, Nancy, 2012. The SES and health gradient: a brief review of the literature. In: Wolfe, B., Evans, W., Seeman, Teresa E. (Eds.), The Biological Consequences of Socioeconomic Inequalities. Russell Sage Foundation, New York.

García-Gómez, Pilar, van Kippersluis, Hans, O’Donnell, Owen, Doorslaer, Eddy van, 2013. Long term and spillover effects of health shocks on employment and income. J. Hum. Resour. 48 (4), 873-909.

Herbert, A.Simon., 1955. A behavioral model of rational choice. Q. J. Econ. 69 (1), 99118.

Huisman, Martijn, Kunst, Anton E., Andersen, Otto, Bopp, Matthias, Borgan, JensKristian, Borrell, Carme, Costa, Giuseppe, Deboosere, Partick, Desplanques, Guy, Donkin, Angela, Gadeyne, Sylvie, Minder, Christoph, Regidor, Enrique, Spadea, Teresa, Valkonen, Tapani, Mackenbach, Johan P., 2004. Socioeconomic inequalities in mortality among elderly people in 11 European populations. J. Epidemiol. Community Health 58, 468-475.

Human Mortality Database. 2017. http://www.mortality.org/, data retrieved on March 2017.

Juster, Robert-Paul, McEwen, Bruce S., Lupien, Sonia J., 2010. Allostatic load biomarkers of chronic stress and impact on health and cognition. Neurosci. Biobehav. Rev. 35, 2-16.

Kahneman, Daniel, Miller, Dale T., 1986. Norm theory: comparing reality to its alternatives. Psychol. Rev. 93 (2), 136-153.

Kahneman, Daniel, Varey, Carol A., 1990. Propensities and counterfactuals: the loser that almost won. J. Pers. Soc. Psychol. 59 (6), 1101-1110.

Karasek, Robert A., 1979. job demands, job decision latitude and mental strain: implications for job design. Adm. Sci. Q. 24, 285-306.

Kawachi, Ichiro, Adler, Nancy E. and William H. Dow. 2010. "Money, Schooling, and Health: Mechanisms and Causal Evidence." Annals of the New York Academy of Science 1186, The Biology of Disadvantage: Socioeconomic Status and Health: 56-68.

Kitagawa, Evelyn M., Hauser, Philip M., 1973. Differential Mortality in the United States: A Study in Socioeconomic Epidemiology. Harvard University Press, Cambridge, MA. 
Kouvonen, Anne, Kivimäki, Mika, Virtanen, Marianna, Pentti, Jaana, Vahtera, Jussi, 2005. Work stress, smoking Status, and smoking intensity: an observational study of 49190 employees. J. Epidemiol. Comm. Health 59, 63-69.

Kristenson, Margereta, Erikson, H.R., Sluiter, J.K., Starke, D., Ursin, H., 2004. Psychobiological mechanisms of socioeconomic differences in health. Soc. Sci. Med. 58, 1511-1522.

Kubzansky, Laura D., Kawachi, Ichiro, Sparrow, David, 1999. Socioeconomic Status, hostility, and risk factor clustering in the normative aging study: any help form the concept of allostatic load? Ann. Behav. Med. 21 (4), 330-338.

Kuhn, Andreas, Lalive, Rafael, Zweimüller, Josef, 2009. The public health costs of job loss. J. Health Econ. 28 (6), 1099-1115.

László, Krisztina D., Pikhart, Hynek, Kopp, M.ária S., Bobak, Martin, Pajak, Andrzej, Malyutina, Sofia, Salavecz, Gyöngyvér, Marmot, Michael, 2010. Job insecurity and health: a study of 16 European countries. Soc. Sci. Med. 70 (6-3), 867-874.

Lazarus, Richard S., 1993. From psychological stress to the emotions: a history of changing outlooks. Annu. Rev. Psychol. 44, 1-21.

Leive, Adam., 2018. Dying to win? Olympic Gold medals and longevity. J. Health Econ. 61, 193-204.

Lipowicz, Anna, Szklarska, Alicja, Mitas, Andrzej W., 2016. Biological costs of economic transition: stress levels during the transition from communism to capitalism in Poland. Econ. Hum. Biol. 21, 90-99.

Loomes, Graham, Sugden, Robert, 1986. Disappointment and dynamic inconsistency in choice under uncertainty. Rev. Econ. Stud. 53, 271-282.

Lupien, Sonia J., Maheu, F., Tu, M., Fiocco, A., Schramek, T.E., 2007. The effects of stress and stress hormones on human cognition: implications for the Field of brain and cognition. Brain Cogn. 65, 209-237.

Mackenbach, Johan P., Kulhánová, Ivana, Artnik, Barbara, Bopp, Matthias, Borrell, Carme, Clemens, Tom, Costa, Giuseppe, Dibben, Chris, Kalediene, Ramune, Lundberg, Olle, Martikainen, Pekka, Menvielle, Gwenn, Östergren, Olof, Prochorskas, Remigijus, Rodríguez-Sanz, Maica, Strand, Bjørn Heine, Looman, Casper W.N., Rianne de, Gelder, 2016. Changes in mortality inequalities over Two decades: register based study of European countries. Br. Med. J. 353, i1732.

Maffetone, Philip B., Laursen, Paul B., 2016. Athletes: fit but unhealthy? Sports Med.-Open 2, 24. doi:http://dx.doi.org/10.1186/s40798-016-0048-x.

Markman, Keith D., Gavanski, Igor, Sherman, Steven J., McMulllen, Matthew N., 1993. The mental simulation of better and worse possible worlds. J. Exp. Soc. Psychol. 29, 87-109.

Marmot, Michael G., Smith, George D., Stansfeld, Stephen, Patel, Chandra, North, Fiona, Head, Jenny, White, Ian, Brunner, Eric, Feeny, Amanda, 1991. Health inequalities among British civils servants: the whitehall II study. Lancet 337 (8754), 1387-1393.

Matthews, Karen A., Gallo, Linda C., Taylor, Shelley E., 2010. Are psychosocial factors mediators of socioeconomic Status and health connections? A progress report and blueprint for the future. Ann. N.Y. Acad. Sci. 1186, 146-173 (Issue: The Biology of Disadvantage).

McEwen, Bruce S., 1998. Protective and damaging effects of stress mediators. N. Engl. J. Med. 322, 173-177.

McEwen, Bruce S., 2007. Physiology and neurobiology of stress and adaptation: Central role of the brain. Physiol. Rev. 87, 873-904.

McEwen, Bruce S., 2008. Central effects of stress hormones in health and disease: understanding the protective and damaging effects of stress and stress mediators. Eur. J. Pharmacol. 583 (2-3), 174-185.

McEwen, Bruce S., Gianaros, Peter J., 2010. Central role of the brain in stress and adaptation: Links to socioeconomic Status, health, and disease. Ann. N.Y. Acad. Sci. 1186, 5-23 (Issue: The Biology of Disadvantage).

McEwen, Bruce S., Sapolsky, Robert M., 1995. Stress and cognitive function. Curr. Opin. Neurobiol. 5, 205-216.

McGraw, A.Peter, Mellers, Barbara A., Telock, Philip E., 2005. Expectations and emotions of olympic athletes. J. Exp. Soc. Psychol. 41, 438-446.
Medvec, Victoria H., Savitsky, Kenneth, 1997. When doing better means feeling worse: the effects of categorical cutoff points on counterfactual thinking and satisfaction. J. Pers. Soc. Psychol. 72 (6), 1284-1296.

Medvec, Victoria H., Madey, Scott F., Gilovich, Thomas, 1995. When less is more: counterfactual thinking and satisfaction among olympic medalists. J. Pers. Soc. Psychol. 69 (4), 603-610.

Nofsinger, John R., Patterson, Fernando M., Shank, Corey A., 2018. Decision-making, financial risk aversion, and behavioral biases: the role of testosterone and stress. Econ. Hum. Biol. 29, 1-16.

Rablen, Matthew D., Oswald, Andrew J., 2008. Mortality and immortality: the nobel prize as an experiment into the effect of Status upon longevity. J. Health Econ. 27, 1462-1471.

Redelmeier, Donald A., Singh, Sheldon M., 2000. Survival in academy awardwinning actors and actresses. Ann. Intern. Med. 134 (10), 955-962.

Roese, Neil J., 1997. Counterfactual thinking. Psychol. Bull. 121 (1), 133-148.

Rogers, Richard G., Powell-Griner, Eva, 1991. Life expectancies of cigarette smokers and nonsmokers in the United States. Soc. Sci. Med. 32, 1151-1159.

Sapolsky, Robert M., 2000. Stress hormones: Good and Bad. Neurobiol. Dis. 7, 540542.

Sapolsky, Robert.M., 2005. The influence of social hierarchy on primate health. Science 308 (5722), 648-652.

Sapolsky, Robert M., Krey, Lewis C., McEwen, Bruce S., 1986. the neuroendocrinology of stress and aging: the glucocorticoid Cascade hypothesis. Endocr. Rev. 7 (3), 284-301.

Seeman, Teresa E. McEwen, Bruce S., Rowe, John W., Singer, Burton H., 2001 Allostatic load as a marker of cumulative biological risk: MacArthur studies of successful aging. Proc. Nat. Acad. Sci. (PNAS) 98 (8), 4770-4775.

Seinfeld, Jerry., 1998. I'm Telling You for the Last Time." Olympics. Broadhurst Theatre, New York City. https://www.youtube.com/watch?v=vAxsA08Yzf8.

Siegrist, Johannes., 1996. Adverse health effects of High-Effort/Low-reward conditions. J. Occup. Health Psychol. 1 (1), 27-41.

Siegrist, Johannes, Marmot, Michael, 2004. Health inequalities and the psychosocial environment - Two scientific challenges. Soc. Sci. Med. 58 (8), 1463-1473.

Smith, James P., 1999. healthy bodies and Thick wallets: the dual relation between health and economic Status. J. Econ. Perspect. 13 (2), 145-166.

Sports Reference. 2014. "Olympics Statistics and History”, http://www.sportsreference.com/olympics/ or https://www.olympic.org/ (data retrieved in December 2014)

Stringhini, Silvia, Sabia, S.éverine, Shipley, Martin, Brunner, Eric, Hermann, Nabi, Kivimäki, Mika, Singh-Manoux, Archana, 2010. Association of socioeconomic position with health behaviors and mortality. J. Am. Med. Assoc. 303 (12), 1159 1166.

Sylvestre, M.P., Huszti, E., Hanley, J.A., 2006. Do oscar winners live longer than less successful peers? A reanalysis of the evidence. Ann. Intern. Med. 145 (5), 361 363.

Umberson, D., Lui, H., Recezek, C., 2008. Stress and health behavior over the life Course. Adv. Life Course Res. 13, 19-44.

Van Dijk, Wilco W., van der Pligt, Joop, Zeelenberg, Marcel, 1999. effort invested in vain: the impact of effort on the intensity of disappointment and regret. Motiv. Emot. 23, 203-220.

Van Kippersluis, Hans, O’Donnell, Owen, Doorslaer, Eddyvan, 2011. Long run returns to education: does schooling lead to an extended Old age? J. Hum. Resour. 46 (4) 695-721.

Young, David C., 1994. On the source of the olympic credo. OLYMPIKA: Int. J. Olympic Stud. 3, 17-25.

Zwiers, R., Zandtvoord, F.W.A., Engelaer, F.M., Bodegom, van, D., Ouderaa, van der, F.J G., Westedorp, G.J., 2012. Mortality in former olympic athletes: retrospective cohort analysis. Br. Med. J. 345, e7456. 